\title{
Downregulation of thymidylate synthase with arsenic trioxide in lung adenocarcinoma
}

\author{
SZE-KWAN LAM ${ }^{1}$, JUDITH CHOI-WO MAK ${ }^{1}$, CHUN-YAN ZHENG ${ }^{1}$, \\ YUAN-YUAN LI ${ }^{1}$, YOK-LAM KWONG ${ }^{2}$ and JAMES CHUNG-MAN HO ${ }^{1}$
}

Divisions of ${ }^{1}$ Respiratory Medicine and ${ }^{2}$ Haematology, Medical Oncology and Bone Marrow Transplantation, Department of Medicine, The University of Hong Kong, Queen Mary Hospital, Hong Kong SAR, P.R. China

Received January 6, 2014; Accepted March 4, 2014

DOI: $10.3892 /$ ijo.2014.2364

\begin{abstract}
Thymidylate synthase (TYMS) is an important chemotherapeutic target in non-small cell lung cancer (NSCLC). Arsenic trioxide (ATO) has been shown to suppress TYMS in a colonic cancer model. We examined the effects of TYMS suppression by ATO in lung adenocarcinoma. A panel of 4 lung adenocarcinoma cell lines was used to determine the effects of ATO treatment on cell viability, TYMS expression (protein and mRNA), E2F1 protein expression and TYMS activity. TYMS knockdown and overexpression were performed. Tumor growth inhibition in vivo was studied using a nude mouse xenograft model. ATO showed antiproliferative effects with clinically achievable concentrations (around 1.1-6.9 $\mu \mathrm{M}$ ) in 4 lung adenocarcinoma cell lines. Downregulation of TYMS protein and mRNA expression, reduced TYMS activity, and suppressed E2F1 expression were demonstrated in lung adenocarcinoma with ATO. Cell viability was reduced by $15-50 \%$ with TYMS knockdown. Overexpression of TYMS led to a 2.7-fold increase in $\mathrm{IC}_{50}$ value with ATO treatment in $\mathrm{H} 358$ cells, but not in $\mathrm{H} 23$ cells. Using a xenograft model with $\mathrm{H} 358$ cell line, relative tumor volume was reduced to $44 \%$ that of the control following 8 days of treatment with $7.5 \mathrm{mg} / \mathrm{kg}$ ATO, and associated with significant downregulation of TYMS protein expression. In conclusion, ATO has potent in vitro and in vivo activity in lung adenocarcinoma, and is partially mediated by transcriptional downregulation of TYMS.
\end{abstract}

\section{Introduction}

Lung cancer is the most common and fatal cancer in the world over the past decade. In 2008, the incidence and mortality rates of lung cancer, based on GLOBOCAN project by World Health

Correspondence to: Dr James C. Ho, Department of Medicine, The University of Hong Kong, Queen Mary Hospital, Pokfulam, Hong Kong SAR, P.R. China

E-mail: jhocm@hku.hk

Key words: lung adenocarcinoma, arsenic trioxide, thymidylate synthase, xenograft
Organization, were 12.7 and $18.2 \%$ of all cancers respectively (http://globocan.iarc.fr/). Non-small cell lung carcinoma (NSCLC) accounts for about $85 \%$ of all lung cancers, with adenocarcinoma being the predominant histologic type. Despite advances in targeted therapy for NSCLC, systemic chemotherapy remains the main treatment for most cases.

Thymidylate synthase (TYMS) is an essential enzyme for biosynthesis of thymidylate that is critical for DNA synthesis. TYMS generates deoxythymidine-5'-monophosphate (dTMP) by catalyzing the reductive methylation of 2'-deoxyuridinemonophosphate (dUMP) via transfer of a methylene group from $\mathrm{CH} 2 \mathrm{H} 4$ folate. dTMP is further phosphorylated to the triphosphate state (dTTP) that acts as a precursor for DNA synthesis (1). Overexpression of TYMS has been observed in different cancers (2-7) and has thus become one of the important targets for anticancer therapy.

Arsenic trioxide (ATO) has been used historically in Traditional Chinese Medicine for more than 2,000 years. Its key role in the treatment of acute promyelocytic leukemia was approved by the US Food and Drug Administration at the turn of the millennium. Recent studies have demonstrated TYMS suppression by ATO that accounts for the synergism of ATO with 5-fluorouracil in suppression of colorectal (8) and liver cancer cells (9). The aim of this study was to investigate the potential therapeutic role of TYMS suppression by ATO in lung adenocarcinoma.

\section{Materials and methods}

Cell lines and reagents. A panel of four lung adenocarcinoma cell lines (NCI-H23, NCI-H358, NCI-H1650 and NCI-H1975 cells) was purchased from the American Type Culture Collection (Manassas, VA, USA). Cells were cultured in RPMI-1640 medium (Gibco ${ }^{\circledR}$, Life Technologies, Carlsbad, CA, USA) supplemented with $10 \%$ fetal bovine serum (FBS) (Life Technologies) in a humidified atmosphere of $5 \% \mathrm{CO}_{2}$ at $37^{\circ} \mathrm{C}$. ATO (Sigma-Aldrich, St. Louis, MO, USA) was dissolved in $1.65 \mathrm{M}$ sodium hydroxide with $\mathrm{pH}$ adjusted to 7.4 by $6 \mathrm{M}$ hydrochloric acid before use.

Cell viability assay. Cells were seeded and $200 \mu \mathrm{l}$ of serially diluted ATO solutions added, with medium used as the negative control. After incubation, cell viability was measured by 
MTT (3-(4,5-dimethylthiazol-2-yl)-2,5-diphenyltetrazolium bromide) assay (Sigma-Aldrich). Absorbance at $595 \mathrm{~nm}$ was measured using a microplate reader Fluo Star Optima (Bmg Labtec GmbH, Ortenberg, Germany). Results were measured in triplicates.

Western blot analysis for protein expression. ATO-treated cells were lysed with RIPA lysis buffer. Protein concentration was determined using the Bradford assay (Bio-Rad, Berkeley, CA, USA). The supernatant (30-100 $\mu \mathrm{g}$ protein) was subjected to $10 \%$ sodium dodecyl sulfate-polyacrylamide gel electrophoresis, and then transferred to a nitrocellulose membrane (GE Healthcare, Buckinghamshire, UK). The membranes were incubated overnight at $4^{\circ} \mathrm{C}$ with primary antibodies against $\beta$-actin (Sigma-Aldrich), TYMS and E2F1 (Cell Signaling technology, Danvers, MA, USA). Further incubation was performed with the corresponding horseradish peroxidase (HRP)-conjugated secondary antibody (Cell Signaling Technology). Detection was performed using an enhanced chemiluminescence (ECL) kit (GE Healthcare). Relative protein expression was normalized with $\beta$-actin.

Quantification of TYMS mRNA. Total cellular RNA was extracted using a standard TRIzol/chloroform method. The PowerSYBR ${ }^{\circledR}$-Green Cells-to- $\mathrm{C}_{\mathrm{T}}{ }^{\mathrm{TM}}$ kit (Life Technologies) was used for reverse transcription and quantitative polymerase chain reaction (qPCR). Incubation of extracted RNA with RT Master mix was carried out at $37^{\circ} \mathrm{C}$ for $60 \mathrm{~min}$, followed by inhibition of reverse transcription at $95^{\circ} \mathrm{C}$ for $5 \mathrm{~min}$ and storage at $4^{\circ} \mathrm{C}$. cDNA was mixed with PowerSYBR-Green PCR Master mix, TYMS forward (TCAAGGGATCCACAAATGCT) and reverse (TCTGTCGTCAGGGTTGGTTT) primers. GAPDH primer served as internal control. The real-time PCR cycling conditions included enzyme activation $\left(95^{\circ} \mathrm{C}\right.$ for $\left.10 \mathrm{~min}\right), \mathrm{PCR}$ cycle $\left(95^{\circ} \mathrm{C}\right.$ for $15 \mathrm{sec}, 60^{\circ} \mathrm{C}$ for $1 \mathrm{~min}, 40$ cycles) and dissociation curve (default setting) by StepOnePlus Real-Time PCR System (Applied Biosystems, Foster City, CA, USA). The relative expression was calculated using the following equations (10): $\Delta \mathrm{C}_{\mathrm{T}}=\mathrm{C}_{\mathrm{T}}$ (TYMS) - $\mathrm{C}_{\mathrm{T}}(\mathrm{GAPDH}) ; \Delta \Delta \mathrm{C}_{\mathrm{T}}=\Delta \mathrm{C}_{\mathrm{T}}$ (treatment) $-\Delta \mathrm{C}_{\mathrm{T}}$ (control); relative expression $=1 / 2^{\Delta \Delta \mathrm{C}_{\mathrm{T}}}$.

TYMS activity assay. ATO-treated cells were then incubated with $3 \mu 1\left[5-{ }^{3} \mathrm{H}\right]-d U M P$ (American Radiolabeled Chemicals, St. Louis, MO, USA) in fresh medium for $2 \mathrm{~h}$. TYMS converts [5- $\left.{ }^{3} \mathrm{H}\right]$-dUMP into dTMP and ${ }^{3} \mathrm{H}_{2} \mathrm{O}$, with the amount of ${ }^{3} \mathrm{H}_{2} \mathrm{O}$ directly proportional to TYMS activity. After incubation, the culture medium was transferred to a micro-centrifuge tube containing $150 \mu 115 \%$ charcoal with $4 \%$ trichloroacetic acid. This mixture was centrifuged, with the supernatant mixed with scintillation fluid and measured by scintillation counter (11). TYMS activity = total scintillation count of sample/total scintillation count of control.

TYMS siRNA knockdown. Cells were incubated for $6 \mathrm{~h}$ with a mixture of TYMS (sc-44978) or control (sc-37007) siRNA and transfection reagent (Santa Cruz Biotechnology Inc., Santa Cruz, CA, USA) in plain medium. The transfected cells were maintained in $1 \%$ FBS-containing medium for 3 days. The TYMS protein expression and cell viability were measured by western blot analysis and MTT assay, respectively.
Table I. The $\mathrm{IC}_{50}$ values of different adenocarinoma cell lines after incubation of ATO for 48 or $72 \mathrm{~h}$.

\begin{tabular}{lcccc}
\hline NSCLC & $\mathrm{H} 23$ & $\mathrm{H} 358$ & $\mathrm{H} 1650$ & $\mathrm{H} 1975$ \\
\hline $\mathrm{IC}_{50}(\mu \mathrm{M})(48 \mathrm{~h})$ & $1.9 \pm 1.8$ & $16.5 \pm 2.0$ & $3.6 \pm 1.7$ & $2.8 \pm 1.5$ \\
$\mathrm{IC}_{50}(\mu \mathrm{M})(72 \mathrm{~h})$ & $0.6 \pm 0.1$ & $8.0 \pm 3.5$ & $4.1 \pm 2.1$ & $1.3 \pm 0.6$ \\
\hline
\end{tabular}

TYMS overexpression. Cells were incubated for $6 \mathrm{~h}$ with a mixture of TYMS or control plasmid (PCMV-XL5) (Origene, Rockville, MD, USA) and Lipofectamine 2000 (Life Technologies) in plain medium. Transfected cells were maintained in $1 \%$ FBS-containing medium for $40 \mathrm{~h}$, then treated for $72 \mathrm{~h}$ with different concentrations of ATO in $1 \%$ (H23 cells) or 10\% (H358 cells) FBS-containing medium. The TYMS protein expression and cell viability were measured.

Tumor growth inhibition in vivo. Tumor xenografts were established with NCI-H358 cells by subcutaneous injection of $1.2 \times 10^{7}$ cells in PBS into the back of nude mice (female, 4-week-old, 10-12 g, BALB/cAnN-nu; Charles River Laboratories, Wilmington, MA, USA). Tumors were allowed to reach no more than $300 \mathrm{~mm}^{3}$ before mice were randomised to one of the treatment groups. ATO (dissolved in PBS) at $7.5 \mathrm{mg} / \mathrm{kg}$ $(n=8)$, or an equal volume of PBS as control $(n=7)$, was administered intraperitoneally, daily for up to 14 days. Tumor growth (measured by standard caliper) and body weight of mice were monitored on alternate days. Tumor volume (V) (before and during treatment) was calculated according to the formula $\mathrm{V}=$ (length $\mathrm{x}$ width $\mathrm{x}$ width)/2 (12). Mice were sacrificed following completion of treatment, and tumor xenografts excised and snap-frozen in liquid nitrogen. They were then homogenized for preparation of protein lysates in lysis buffer for western blot analysis. The study protocol using an in vivo model of tumor xenografts in nude mice was approved by the Committee on the Use of Live Animals in Teaching and Research (CULATR) of the University of Hong Kong (CULATR reference no. 2510-11).

Statistical analysis. Data from triplicate experiments are presented as mean $\pm \mathrm{SD}$. Comparison between groups was performed using Student's two-tailed t-test by Prism (GraphPad Software, La Jolla, CA, USA). A p-value $<0.05$ was considered statistically significant.

\section{Results}

In vitro activity of ATO in lung adenocarcinoma. Dosedependent and time-dependent antiproliferative effects of ATO with clinically achievable concentrations (around 1.1-6.9 $\mu \mathrm{M}$ ) were evident in most lung adenocarcinoma cell lines. $\mathrm{The}_{\mathrm{IC}}$ value (mean $\pm \mathrm{SD}$ ) was obtained for 48 and $72 \mathrm{~h}$ of ATO treatment (Table I).

TYMS protein and mRNA expression with ATO treatment. H23 cells revealed the highest TYMS protein expression. The TYMS expression levels in H358, H1650 and H1975 cells were comparable (Fig. 1A). Following 48-h treatment with ATO, TYMS protein expression was significantly suppressed dose- 
A
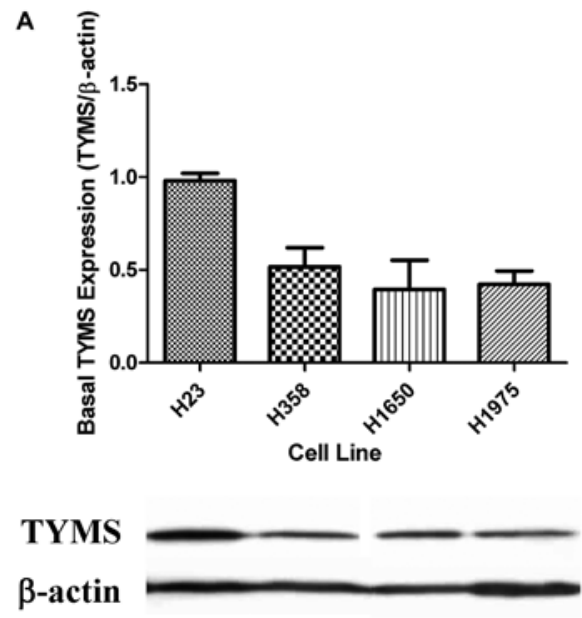

B
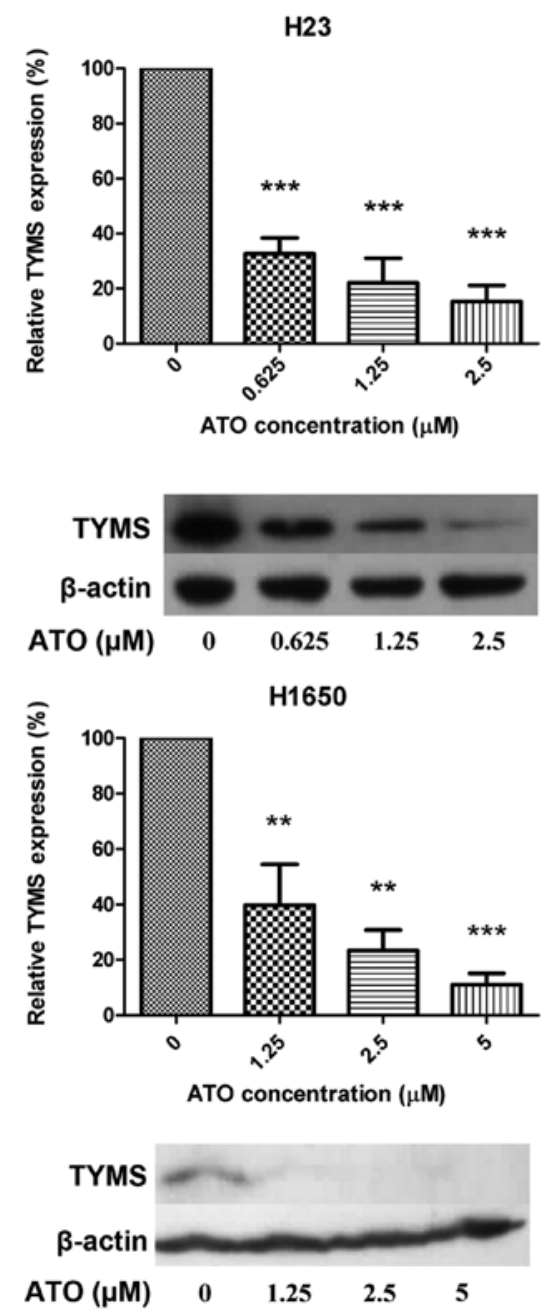
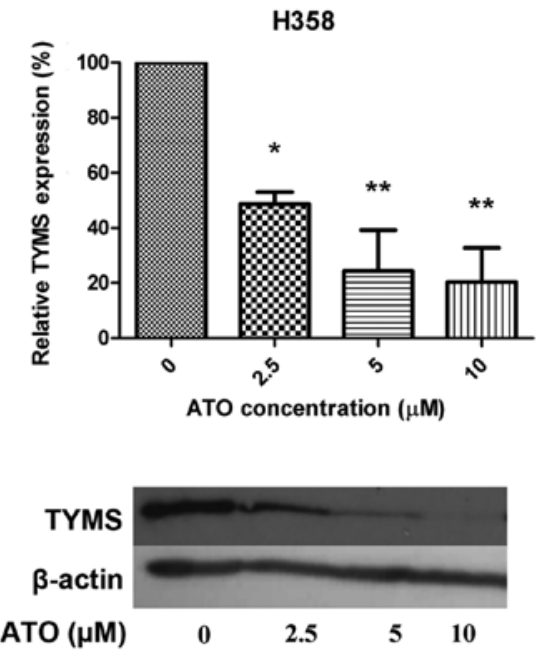

H1975
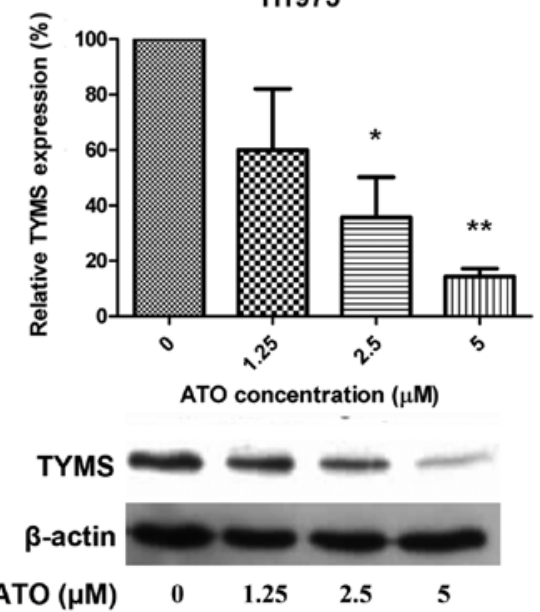

Figure 1. (A) Basal TYMS protein expression, determined by western blot analysis with $\beta$-actin normalization, in different lung adenocarcinoma cell lines. (B) Decreased expression of TYMS protein by incubation with ATO in RPMI-1640 medium for $48 \mathrm{~h}$.

dependently (Fig. 1B). In addition, TYMS mRNA expression was significantly decreased in H23, H358 and H1650 cells, suggesting transcriptional regulation by ATO treatment (Fig. 1C).

E2F1 protein expression with ATO treatment. In addition to reduction in TYMS mRNA, ATO also significantly reduced expression of E2F1 protein (Fig. 1D).
TYMS activity with ATO treatment. Basal TYMS activity is shown in Fig. 2A. The TYMS activity was significantly reduced in all 4 cell lines with ATO treatment (Fig. 2B).

Cell viability with silenced TYMS. The effect of TYMS knockdown on cell viability was studied using siRNA targeting TYMS. The efficiency of siRNA knockdown was confirmed 

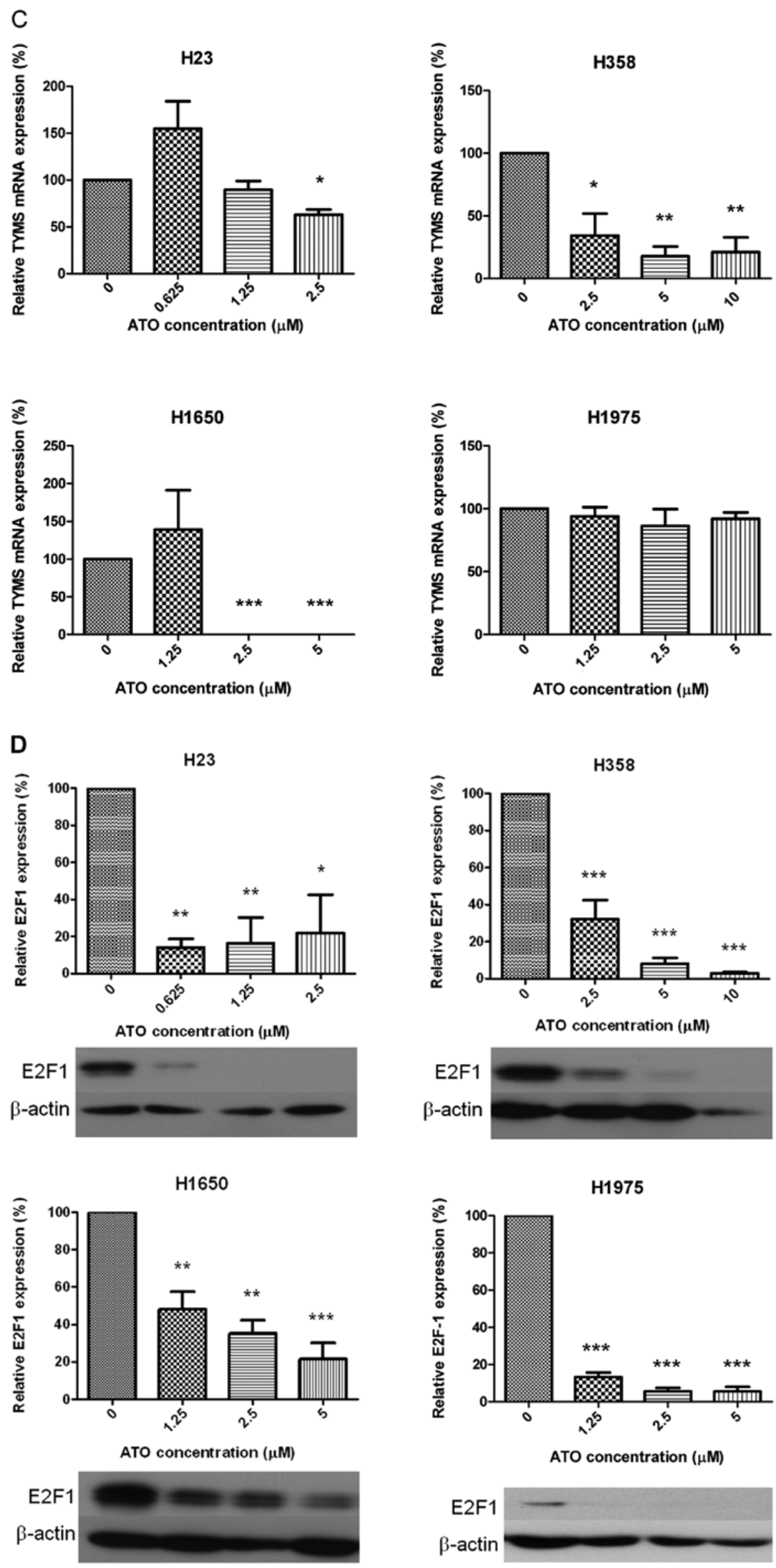

Figure 1. Continued. (C) Downregulation of TYMS mRNA in a dose-dependent manner by ATO, except in H1975. The measurement of TYMS mRNA was performed by qPCR. (D) ATO induced a decrease in protein expression of E2F1, determined by western blot analysis with $\beta$-actin normalization, in different cell lines. Results were measured in triplicate experiments. Statistical significance $\left({ }^{*} \mathrm{p}<0.05,{ }^{* *} \mathrm{p}<0.01,{ }^{* * *} \mathrm{p}<0.001\right)$ is indicated for comparison with control. 
A

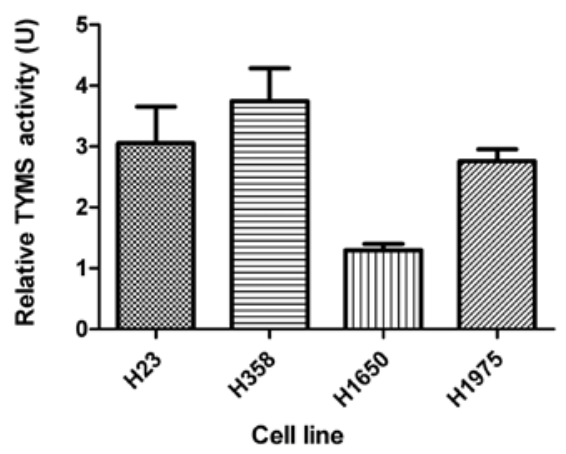

B

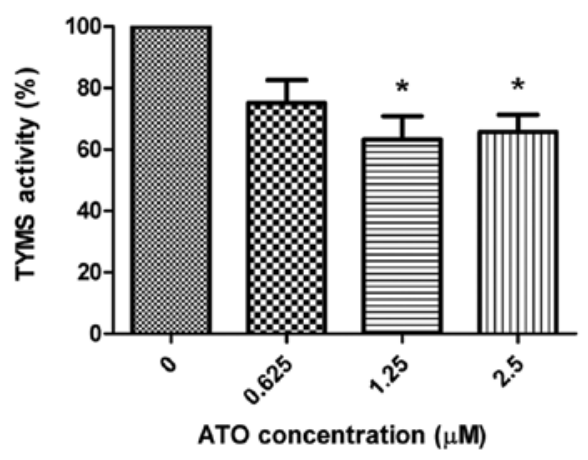

H1650

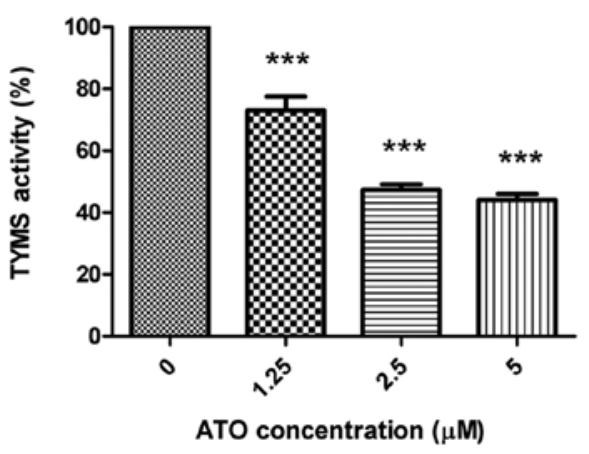

H358

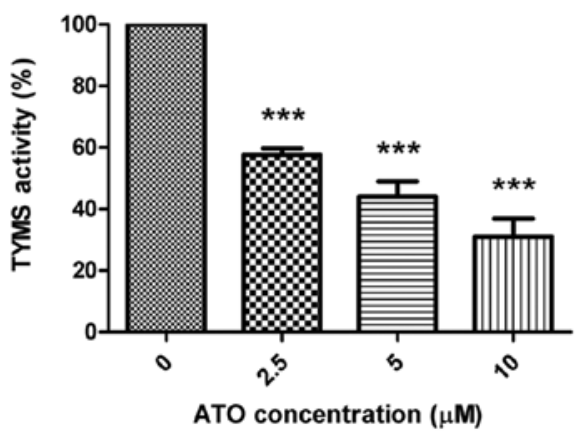

H1975

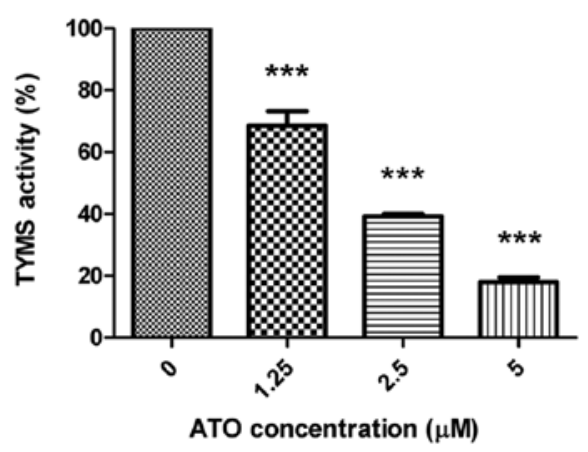

Figure 2. (A) Basal TYMS activity in different cell lines. (B) TYMS activity of cells after exposure to ATO for 48 h. The TYMS activity was measured by production of ${ }^{3} \mathrm{H}_{2} \mathrm{O}$ from $\left[5-{ }^{3} \mathrm{H}\right]$-dUMP. Results were measured in triplicate experiments. Statistical significance $\left({ }^{*} \mathrm{p}<0.05,{ }^{* *} \mathrm{p}<0.01,{ }^{* * *} \mathrm{p}<0.001\right)$ is indicated for comparison with control.

by a relative reduction in TYMS protein to $<30 \%$. With TYMS knockdown, cell viability was reduced by 40, 50, 20 and $15 \%$ in H23, H358, H1650 and H1975 cells, respectively (Fig. 3A-D). A higher concentration of TYMS siRNA (30 nM) caused severe cell death in $\mathrm{H} 23$ and $\mathrm{H} 358$ cells (data not shown).

Overexpression of TYMS and ATO treatment. Overexpression of TYMS was performed in H23 and H358 cells, via transfection with TYMS plasmid (pTYMS) and control plasmid (pCTL), to study the effect of ATO. The efficiency of TYMS overexpression was shown by increased TYMS protein expression 4.7 and 4-fold in $\mathrm{H} 23$ and $\mathrm{H} 358$ cells, respectively. Comparing with control treatment, there was no significant difference in TYMS activity in the pTYMS and pCTL groups (data not shown). The cell number increased by about $60 \%$ following TYMS overexpression compared with control in both cell lines (data not shown). In $\mathrm{H} 23$ cells, the $\mathrm{IC}_{50}$ values $(72 \mathrm{~h})$ for ATO treatment were similar for the pTYMS and pCTL groups (Fig. 4A). In H358 cells, the $\mathrm{IC}_{50}$ values (72 h) in pTYMS and pCTL groups were 2.5 and $0.67 \mu \mathrm{M}$, respectively (Fig. 4A). The basal expression of E2F1 was unchanged in H23 cells following transfection with pTYMS, but decreased in H358 cells (Fig. 4B). In both cell lines, TYMS protein and E2F1 expression levels in both groups were downregulated dose-dependently following ATO treatment (Fig. 4B-C).

In vivo effect of ATO on tumor xenografts. By day 5 following implantation of $\mathrm{H} 358$ cells, successful development of tumors was noted. There was no significant difference in baseline tumor volume between groups before drug treatment. The 
A
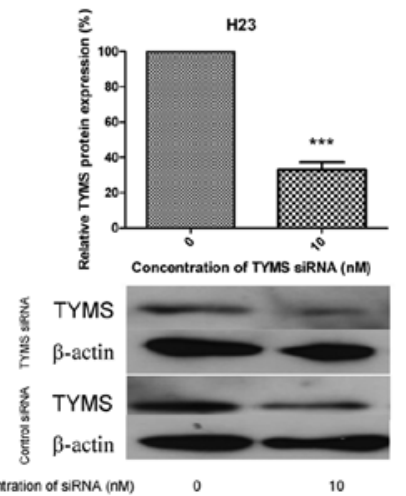

C
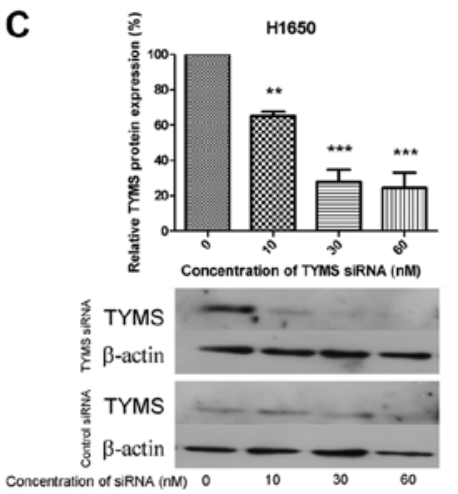

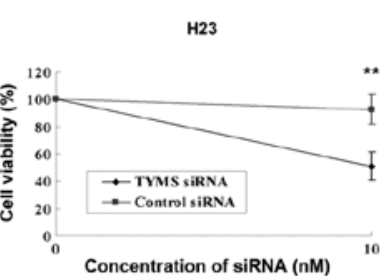

B

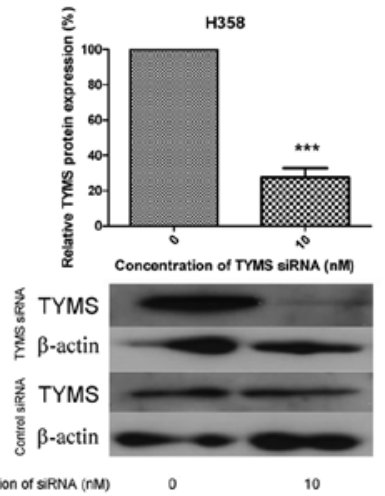

D

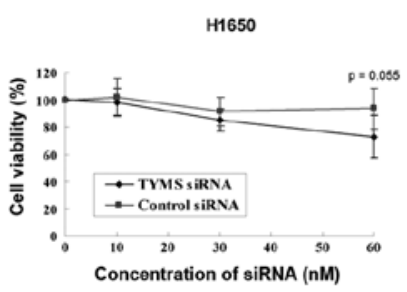

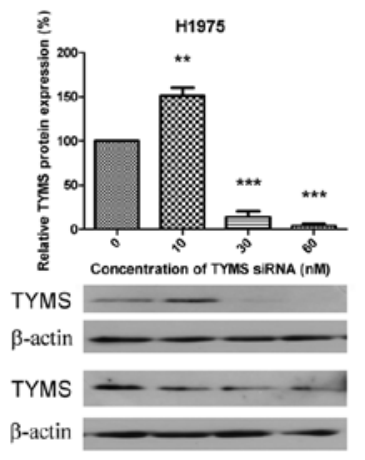
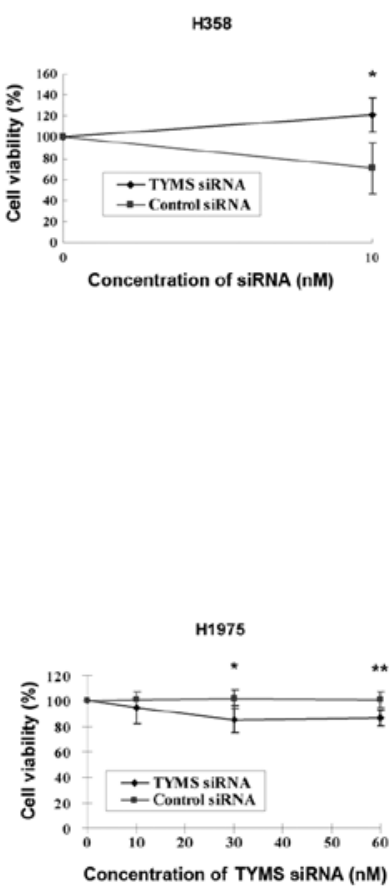

Figure 3. Effect of TYMS-targeted siRNA on TYMS protein expression and cell viability in (A) H23, (B) H358, (C) H1650 and (D) H1975 cells. Cells, transfected with TYMS or control siRNA for $6 \mathrm{~h}$, were incubated in 1\% FBS-containing RPMI-1640 medium for 3 days. The relative TYMS protein levels (by western blot analysis) with TYMS-siRNA treatment were normalized with that of control siRNA at same concentrations. The cell viability was determined by MTT assay. Results were measured in triplicate experiments. Statistical significance $\left({ }^{*} \mathrm{p}<0.05,{ }^{* *} \mathrm{p}<0.01,{ }^{* * *} \mathrm{p}<0.001\right)$ is indicated for comparison with control.

change in relative tumor size in the control and treatment groups over an 8-day period is shown in Fig. 5A. At this time, the relative tumor volume in the ATO-treated group $(7.5 \mathrm{mg} / \mathrm{kg})$ was $44 \%$ that of the control group $(\mathrm{p}<0.05)$. All the mice were alive at the end of treatment. Based on western blot analysis with protein lysates obtained from tumor xenografts after treatment, TYMS protein expression was significantly suppressed in the ATO treatment arm (Fig. 5B).

\section{Discussion}

We have demonstrated in an in vitro model of lung adenocarcinoma, the activity of ATO close to clinically achievable concentrations (around 1.1-6.9 $\mu \mathrm{M})$ (13-15). ATO can act as a potent inhibitor of TYMS at a transcriptional level, and result in reduced in vitro TYMS protein and activity. The mechanistic importance of TYMS inhibition as a novel cytotoxic mechanism of ATO in lung adenocarcinoma has been validated with TYMS knockdown and overexpression experiments that revealed TYMS to be critically involved in cellular proliferation. Antitumor activity of ATO has also been demonstrated in a xenograft model wherein TYMS protein was suppressed.

Over the past decade, major advances in the molecular biology of NSCLC have led to the clinical development of various targeted therapies. Notably, there are now clinically available specific treatment options against epidermal growth factor receptor (EGFR) mutated or anaplastic lymphoma kinase (ALK) gene rearranged NSCLC. Nonetheless, these druggable driver oncogenes exist in only 30 to $40 \%$ of lung adenocarcinoma cases in East Asians, and much less frequently $(<20 \%)$ in Caucasians (16). Systemic chemotherapy remains the cornerstone of first-line treatment for the majority of advanced cases of NSCLC, and the major salvage treatment when targeted therapy fails. A TYMS-targeting approach has emerged as an important strategy for advanced non-squamous NSCLC.

ATO is notoriously poisonous. Despite this, among the traditional Chinese medicines, Pi Shuang (an oral form of ATO) has been used to treat toxic conditions, chronic ulcers and cervical lymphadenopathy (17). The intravenous formulation of ATO has received approval from the US Food and Drug Administration for the treatment of APL, with up to $90 \%$ of patients achieving complete remission (18) and almost 90\% 3 -year disease-free survival (19). The mechanisms of action of ATO have been best described in leukemia, including elevation of reactive oxygen species, loss of mitochondrial membrane potential, and release of cytochrome $c$, followed by activation of caspase cascade and apoptosis (20-25), as well as enhancing SUMOylation and degradation (26,27).

Contrary to this, there have been limited data on the activity and mechanisms of ATO in lung cancer. In the human lung carcinoma PG cell line, ATO has been shown to induce apoptosis with downregulation of Bcl-2 and P-glycoprotein (28). 
A

$\mathrm{H} 23$

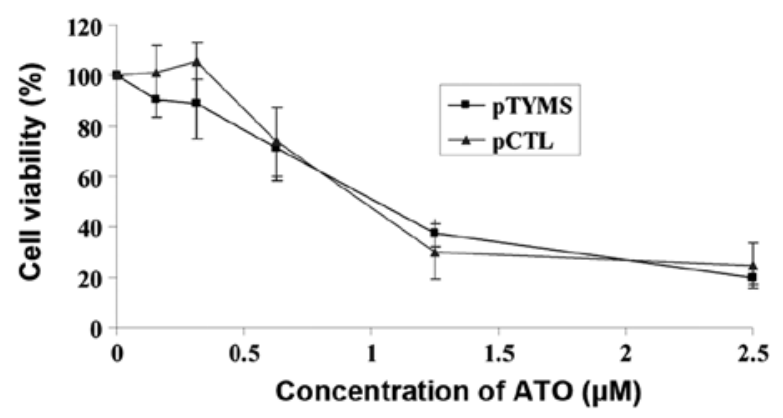

H358

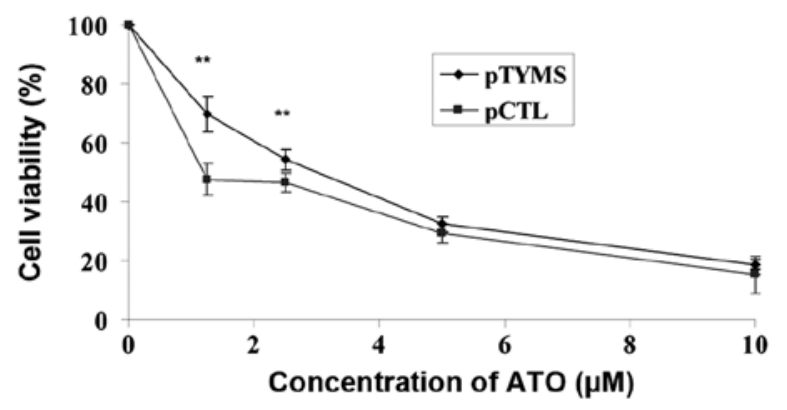

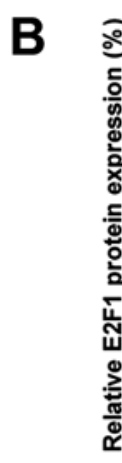
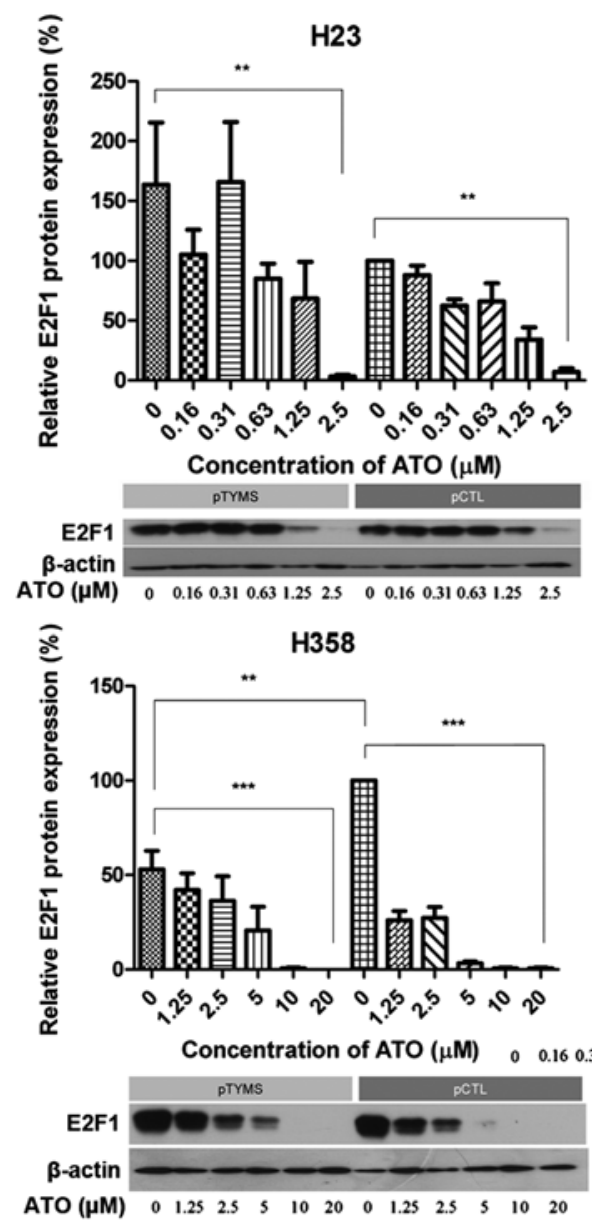

C

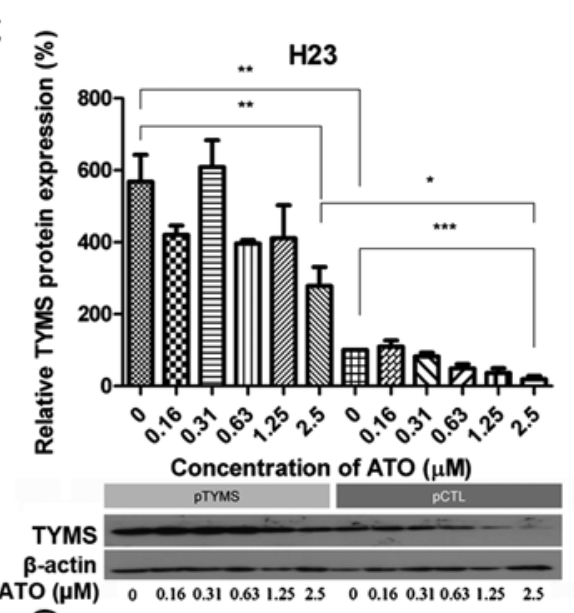

$\stackrel{\frac{9}{\circ}}{(\mu N)}$

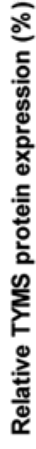

H358

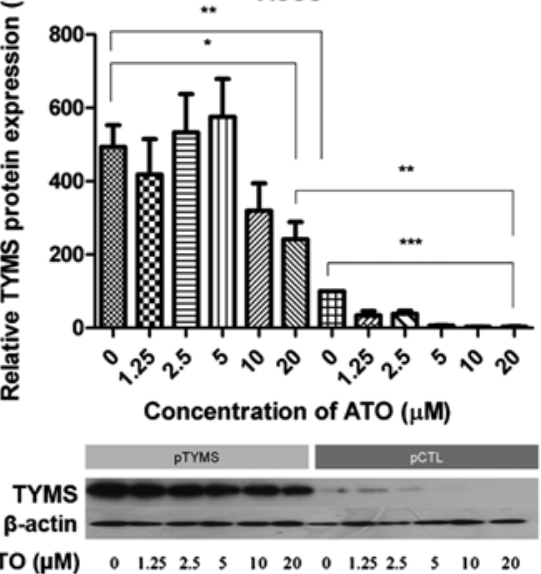

Figure 4. (A) Cell viability, (B) E2F1 and (C) TYMS protein expression after TYMS overexpression in H23 and H358 cells. After transfecting the cells with pTYMS or pCTL for $6 \mathrm{~h}$, the cells were further incubated for $40 \mathrm{~h}$. Cells were then incubated with different concentrations of ATO for $72 \mathrm{~h}$. Cell viability, E2F1 and TYMS protein expression as well as TYMS activity were measured by MTT assay, western blot analysis and TYMS activity assay respectively. Results were measured in triplicate experiments. A p-value $<0.05$ was taken as statistically significant $\left(" \mathrm{p}<0.05,{ }^{* *} \mathrm{p}<0.01,{ }^{* * * *} \mathrm{p}<0.001\right)$. In $\mathrm{H} 23$ cells, the IC $\mathrm{I}_{50}$ values $(72 \mathrm{~h})$ of TYMS and control plasmid transfected cells were 1.02 and $0.97 \mu \mathrm{M}$, respectively. In $\mathrm{H} 358$ cells, the $\mathrm{IC}_{50}$ values (72 $\mathrm{h}$ ) of TYMS and control plasmid transfected cells were 2.5 and $0.67 \mu \mathrm{M}$, respectively. 


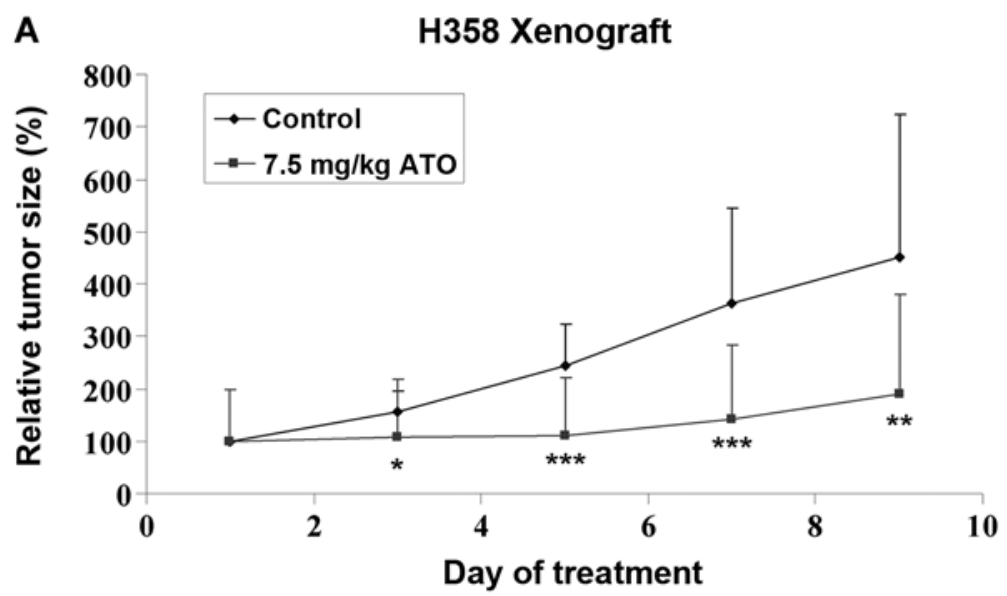

B
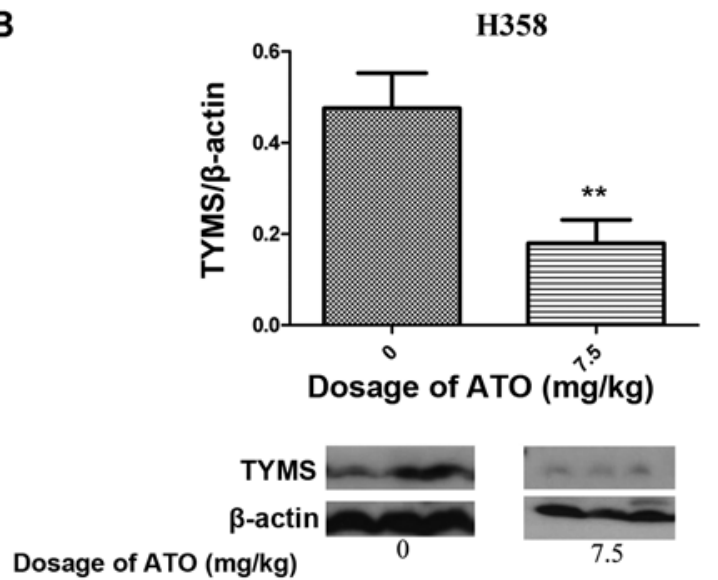

Figure 5. ATO treatment is associated with (A) reduction in relative tumor size and (B) suppression of TYMS protein expression in 7.5 mg/kg ATO treatment group when compared with control group in $\mathrm{H} 358$ xenograft model. Tumor xenografts were established by subcutaneous injection of H358 cells into nude mice. PBS (control) and ATO $(7.5 \mathrm{mg} / \mathrm{kg}$ ) were administered intraperitoneally, daily for 8 days. The relative tumor volume in the treatment group was $44 \%$ of the control group. The protein expression of TYMS was based on western blot analysis with protein lysates obtained from tumor xenografts. Results were measured in triplicate experiments. Statistical significance $\left({ }^{*} \mathrm{p}<0.05,{ }^{* *} \mathrm{p}<0.01,{ }^{* * *} \mathrm{p}<0.001\right)$ is indicated for comparison with control.

Based on experiments in H1355 human lung adenocarcinoma cells, ATO demonstrated cytotoxicity that was accompanied by downregulation of survivin, cleavage of PARP and activation of various MAPKs (29). Interestingly, the non-steroidal anti-inflammatory drug sulindac has been shown to enhance the cytotoxicity of ATO in human lung cancer cells via generation of reactive oxygen species $(30,31)$. A 5-fluorouracil (5-FU)-resistant colorectal cancer cell line model has recently been developed to investigate the potential effect of ATO on TYMS expression. It was found that ATO (up to $1 \mu \mathrm{M}$ ) could downregulate TYMS mRNA and protein expression in a 5-FU resistant cell line (8). In addition, ATO could suppress TYMS mRNA expression in HepG2 hepatic cancer cells, though at a relatively high concentration $(25 \mu \mathrm{M})(9)$.

In our study, ATO reduced TYMS protein in all cell lines, and was associated with suppressed TYMS mRNA levels in 3 of the cell lines. The apparent discordance between mRNA and protein expressions may be related to the translation rate that depends on ribosome occupancy and density, tRNA availability, translation and regulatory factors, changes in protein localization and time delays between transcription, translation and degradation (32). The control of TYMS gene expression is largely regulated by the retinoblastoma 1 (RB1) E2F1 pathway. pRB1 interacts with critical regulatory factors including the E2F family of transcription factors. Phosphorylation of RB1 releases E2F and increases transcription of TYMS (33). Consistent with transcriptional suppression of TYMS, ATO suppressed E2F1 protein expression. We have also resorted to measure TYMS activity. Human TYMS is the only TYMS that exists with an equilibrium of active and inactive conformations. Intriguingly, the inactive human TYMS binds to TYMS mRNA, thus inhibiting TYMS protein synthesis (34). When activated, the active site loop region (residues 181-197) of TYMS is rotated about $180^{\circ}$, so that the catalytic cysteine (C195) is then exposed and oriented towards the dimer interface for its function (35). Upon treatment with ATO, TYMS activity was reduced. The biological significance of TYMS downregulation with ATO has been confirmed with siRNA knockdown of TYMS, reducing cell viability by $15-50 \%$ after significant TYMS suppression. This is consistent with a recent report on RNA interference of TYMS in 30 lung cancer cell lines, which supported the pivotal role of TYMS in cellular proliferation (36). The effect of TYMS overexpression on chemosensitivity to ATO was also studied. Transfection of 
TYMS plasmid increased the cell number by approximately $60 \%$. Although expression of TYMS and cell number was increased, measured TYMS activity was unaltered. One speculation is that the equilibrium of active and inactive conformations shifted back to a basal normal level following cellular proliferation with TYMS plasmid transfection. The active TYMS may also have been degraded before detection since the half-life of human TYMS is only $5 \pm 1 \mathrm{~h}$ (37). TYMS overexpression did not affect the $\mathrm{IC}_{50}$ of ATO treatment in $\mathrm{H} 23$ cells, whereas the $\mathrm{IC}_{50}$ increased 2.7-fold in $\mathrm{H} 358$ cells with TYMS plasmid transfection. The latter supports TYMS as an important target for ATO, in which TYMS overexpression can partially overcome the inhibitory effect of ATO. Since ATO works through complicated and distinct mechanisms, we postulate that alternative mechanisms of cytotoxicity account for persistent chemosensitivity to ATO with TYMS overexpression in $\mathrm{H} 23$ cells. Lastly, a xenograft model in nude mice using the $\mathrm{H} 358$ cell line was developed, demonstrating in vivo activity of ATO via TYMS suppression. The dose of ATO used in our in vivo xenograft model $(7.5 \mathrm{mg} / \mathrm{kg})$ was comparable with other reports $(2.5-10 \mathrm{mg} / \mathrm{kg})(38-42)$.

There are several limitations of this study. First, the number of cell lines in this study is limited and only adenocarcinoma is included. Second, the mechanisms of action of ATO are complex and the predominant actions could vary between different cell lines.

In conclusion, ATO has potent in vitro and in vivo activity in lung adenocarcinoma, at least partially mediated by transcriptional downregulation of TYMS. Since our institution has pioneered the development of an oral formula of ATO for clinical use (43) with a much improved cardiac safety profile (44), its potential clinical application to solid malignancies is highly feasible.

\section{References}

1. Rahman L, Voeller D, Rahman M, et al: Thymidylate synthase as an oncogene: a novel role for an essential DNA synthesis enzyme. Cancer Cell 5: 341-351, 2004.

2. Biason P, Visentin M, Talamini R, et al: Polymorphic thymidylate synthase gene impacts on overall survival of patients with epithelial ovarian cancer after platinum-based chemotherapy. Pharmacogenomics 13: 1609-1619, 2012.

3. Bolocan A, Ion D, Ciocan DN and Paduraru DN: Prognostic and predictive factors in colorectal cancer. Chirurgia (Bucur) 107: 555-563, 2012.

4. Igawa S, Ryuge S, Wada M, et al: Pemetrexed for previously treated patients with non-small cell lung cancer and differences in efficacy according to thymidylate synthase expression. Chemotherapy 58: 313-320, 2012.

5. Ruiz-Tovar J, Fernandez-Contreras ME, Martin-Perez E and Gamallo C: Association of thymidylate synthase and hypoxia inducible factor-1alpha DNA polymorphisms with pancreatic cancer. Tumori 98: 364-369, 2012.

6. Tamatani T, Ferdous T, Takamaru N, et al: Antitumor efficacy of sequential treatment with docetaxel and 5-fluorouracil against human oral cancer cells. Int J Oncol 41: 1148-1156, 2012.

7. Yang Z, Liu HX and Zhang XF: $2 \mathrm{R}$ of thymidylate synthase 5'-untranslated enhanced region contributes to gastric cancer risk: a meta-analysis. Asian Pac J Cancer Prev 13: 1923-1927, 2012.

8. Subbarayan PR, Lee K and Ardalan B: Arsenic trioxide suppresses thymidylate synthase in 5-FU-resistant colorectal cancer cell line HT29 in vitro re-sensitizing cells to 5-FU. Anticancer Res 30: 1157-1162, 2010.

9. Rangwala F, Williams KP, Smith GR, et al: Differential effects of arsenic trioxide on chemosensitization in human hepatic tumor and stellate cell lines. BMC Cancer 12: 402, 2012.
10. Arocho A, Chen B, Ladanyi M and Pan Q: Validation of the 2-DeltaDeltaCt calculation as an alternate method of data analysis for quantitative PCR of BCR-ABL P210 transcripts. Diagn Mol Pathol 15: 56-61, 2006.

11. Pressacco J, Mitrovski B, Erlichman C and Hedley DW: Effects of thymidylate synthase inhibition on thymidine kinase activity and nucleoside transporter expression. Cancer Res 55: 1505-1508, 1995.

12. Kousparou CA, Yiacoumi E, Deonarain MP and Epenetos AA: Generation of a selectively cytotoxic fusion protein against p53 mutated cancers. BMC Cancer 12: 338, 2012.

13. Ardalan B, Subbarayan PR, Ramos Y, et al: A phase I study of 5-fluorouracil/leucovorin and arsenic trioxide for patients with refractory/relapsed colorectal carcinoma. Clin Cancer Res 16: 3019-3027, 2010.

14. Bahlis NJ, McCafferty-Grad J, Jordan-McMurry I, et al: Feasibility and correlates of arsenic trioxide combined with ascorbic acid-mediated depletion of intracellular glutathione for the treatment of relapsed/refractory multiple myeloma. Clin Cancer Res 8: 3658-3668, 2002.

15. Shen ZX, Chen GQ, Ni JH, et al: Use of arsenic trioxide (As2O3) in the treatment of acute promyelocytic leukemia (APL): II. Clinical efficacy and pharmacokinetics in relapsed patients. Blood 89: 3354-3360, 1997.

16. Pao W and Hutchinson KE: Chipping away at the lung cancer genome. Nat Med 18: 349-351, 2012.

17. Au WY: A biography of arsenic and medicine in Hong Kong and China. Hong Kong Med J 17: 507-513, 2011.

18. Soignet SL, Frankel SR, Douer D, et al: United States multicenter study of arsenic trioxide in relapsed acute promyelocytic leukemia. J Clin Oncol 19: 3852-3860, 2001.

19. Gore SD, Gojo I, Sekeres MA, et al: Single cycle of arsenic trioxide-based consolidation chemotherapy spares anthracycline exposure in the primary management of acute promyelocytic leukemia. J Clin Oncol 28: 1047-1053, 2010.

20. Cai X, Shen YL, Zhu Q, et al: Arsenic trioxide-induced apoptosis and differentiation are associated respectively with mitochondrial transmembrane potential collapse and retinoic acid signaling pathways in acute promyelocytic leukemia. Leukemia 14: 262-270, 2000.

21. Jing Y, Dai J, Chalmers-Redman RM, Tatton WG and Waxman S: Arsenic trioxide selectively induces acute promyelocytic leukemia cell apoptosis via a hydrogen peroxidedependent pathway. Blood 94: 2102-2111, 1999.

22. Mahieux R, Pise-Masison C, Gessain A, et al: Arsenic trioxide induces apoptosis in human T-cell leukemia virus type 1- and type 2-infected cells by a caspase-3-dependent mechanism involving Bcl-2 cleavage. Blood 98: 3762-3769, 2001.

23. Park WH, Seol JG, Kim ES, et al: Arsenic trioxide-mediated growth inhibition in MC/CAR myeloma cells via cell cycle arrest in association with induction of cyclin-dependent kinase inhibitor, p21, and apoptosis. Cancer Res 60: 3065-3071, 2000.

24. Shim MJ, Kim HJ, Yang SJ, Lee IS, Choi HI and Kim T: Arsenic trioxide induces apoptosis in chronic myelogenous leukemia K562 cells: possible involvement of p38 MAP kinase. J Biochem Mol Biol 35: 377-383, 2002.

25. Wang ZG, Rivi R, Delva L, et al: Arsenic trioxide and melarsoprol induce programmed cell death in myeloid leukemia cell lines and function in a PML and PML-RARalpha independent manner. Blood 92: 1497-1504, 1998.

26. Lallemand-Breitenbach V, Jeanne M, Benhenda S, et al: Arsenic degrades PML or PML-RARalpha through a SUMO-triggered RNF4/ubiquitin-mediated pathway. Nat Cell Biol 10: 547-555, 2008.

27. Zhang XW, Yan XJ, Zhou ZR, et al: Arsenic trioxide controls the fate of the PML-RARalpha oncoprotein by directly binding PML. Science 328: 240-243, 2010.

28. Han B, Zhou G, Zhang Q, et al: Effect of arsenic trioxide (ATO) on human lung carcinoma PG cell line: ATO induced apoptosis of PG cells and decreased expression of Bcl-2, Pgp. J Exp Ther Oncol 4: 335-342, 2004.

29. Cheng Y, Chang LW and Tsou TC: Mitogen-activated protein kinases mediate arsenic-induced down-regulation of survivin in human lung adenocarcinoma cells. Arch Toxicol 80: 310-318, 2006.

30. Jin HO, Yoon SI, Seo SK, et al: Synergistic induction of apoptosis by sulindac and arsenic trioxide in human lung cancer A549 cells via reactive oxygen species-dependent down-regulation of survivin. Biochem Pharmacol 72: 1228-1236, 2006. 
31. Kim HR, Kim EJ, Yang SH, et al: Combination treatment with arsenic trioxide and sulindac augments their apoptotic potential in lung cancer cells through activation of caspase cascade and mitochondrial dysfunction. Int J Oncol 28: 1401-1408, 2006.

32. De Sousa Abreu R, Penalva LO, Marcotte EM and Vogel C: Global signatures of protein and mRNA expression levels. Mol Biosyst 5: 1512-1526, 2009.

33. Belvedere O, Puglisi F, Di Loreto C, et al: Lack of correlation between immunohistochemical expression of E2F-1, thymidylate synthase expression and clinical response to 5 -fluorouracil in advanced colorectal cancer. Ann Oncol 15 $55-58,2004$.

34. Phan J, Steadman DJ, Koli S, et al: Structure of human thymidylate synthase suggests advantages of chemotherapy with noncompetitive inhibitors. J Biol Chem 276: 14170-14177, 2001.

35. Salo-Ahen OM and Wade RC: The active-inactive transition of human thymidylate synthase: targeted molecular dynamics simulations. Proteins 79: 2886-2899, 2011.

36. Takezawa K, Okamoto I, Tsukioka S, et al: Identification of thymidylate synthase as a potential therapeutic target for lung cancer. Br J Cancer 103: 354-361, 2010.

37. Melo SP, Yoshida A and Berger FG: Functional dissection of the $\mathrm{N}$-terminal degron of human thymidylate synthase. Biochem J 432: 217-226, 2010.

38. Jing Y, Wang L, Xia L, et al: Combined effect of all-trans retinoic acid and arsenic trioxide in acute promyelocytic leukemia cells in vitro and in vivo. Blood 97: 264-269, 2001.
39. Kim J, Lee JJ, Gardner D and Beachy PA: Arsenic antagonizes the Hedgehog pathway by preventing ciliary accumulation and reducing stability of the Gli2 transcriptional effector. Proc Nat Acad Sci USA 107: 13432-13437, 2010.

40. Kinjo K, Kizaki M, Muto A, et al: Arsenic trioxide (As2O3)induced apoptosis and differentiation in retinoic acid-resistant acute promyelocytic leukemia model in hGM-CSF-producing transgenic SCID mice. Leukemia 14: 431-438, 2000.

41. Lallemand-Breitenbach V, Guillemin MC, Janin A, et al: Retinoic acid and arsenic synergize to eradicate leukemic cells in a mouse model of acute promyelocytic leukemia. J Exp Med 189: 1043-1052, 1999.

42. Li Y, Sun X, Wang L, Zhou Z and Kang YJ: Myocardial toxicity of arsenic trioxide in a mouse model. Cardiovasc Toxicol 2: 63-73, 2002.

43. Au WY, Kumana CR, Kou M, et al: Oral arsenic trioxide in the treatment of relapsed acute promyelocytic leukemia. Blood 102: 407-408, 2003

44. Siu CW, Au WY, Yung C, et al: Effects of oral arsenic trioxide therapy on QT intervals in patients with acute promyelocytic leukemia: implications for long-term cardiac safety. Blood 108: 103-106, 2006. 